of a series of handbooks for museum curators. The scheme is ambitious and comprehensive and is divided into seven parts under the following headings : administration, museum technique, archæology, ethnography and folk-life, art, natural and applied sciences, temporary activities and the museums schools services. Each part has a separate editor and is further divided into sections dealing with different aspects of the subject. The seope thus covers the whole field of museum administration and practice. Obviously it will not be possible for the parts and sections to be published in any planned order; but a uniform format is to be observed throughout, and the individual booklets have a sufficient inner margin to be held in loose binding covers.

The first of the set to be published is by Dr. A. A. Moss, now in the Department of Mineralogy at the British Museum (Natural History) and previously at the research laboratory of the British Museum at Bloomsbury, "The Application of X-rays, Gammarays, Ultra-violet and Infra-red Rays to the Study of Antiquities", by A. A. Moss (pp. 16, $9 \frac{3}{4} \times 7 \frac{1}{3}$ in.; $4 s ., 3 s$. to members of Museums Association. London : Museums Association, 1954). It has been numbered Section 4 of Part B (Museum Technique) and deals with a practical account of processes in the study of antiquitios which can be carried out in a museum Iaboratory. It is illustrated by eight pages of halftone plates and one line drawing which vividly demonstrate the detail which is revealed by an examination of objects by wave-lengths outside the limits of visible light. It shows, for example, how the use of X-rays demonstrated the existence of pattern welding in the Sutton Hoo iron swords and silver inlaid ornament in corroded buckles. Dr. Moss also deals with the examination of porcelain, books and manuscripts by ultra-violet and infra-red rays, whereby flaws and otherwise invisible breaks may be detected. The value of such processes in establishing the authenticity of objects is considerable, and the booklet will appeal to those interested in antiques, objets d'art or manuscripts. There are many references to earlier papers and a useful bibliography. We unreservedly commend the booklet to curators and would-be curators of museums and art galleries and indeed to all those interested in antiquities.

\section{Soloman R. Guggenheim Museum, New York}

THE December issue of the Museums Journal states that the Soloman R. Guggenheim Museum is about to be commenced in New York. This spectacular building is in essence a cylindrical structure, rather wider at the top than the bottom, and comprises a continuous gentle ramp spiralling upwards, like a spring, around a central circular well. A shallow dome of concentric rings of glass tubing is supported over the well on a steel and aluminium frame and allows light to penetrate down the centre of the building and be diffused-between the coils of the ramp, which are open-sided, on to the well, like a theatre balcony. Visitors will go by lift to the top and then walk down by way of three-quarters of a mile continuous ramp, the greater part of which will be exhibition space and can be divided by movable screens into rooms and alcoves. Visitors may, moreover, enter or leave at one point on each circuit where a smaller cylindrical structure contains lifts and a steeper, staircase-like ramp. Of particular interest is the almost unbroken window slit running around the top of the outer wall of the gallery and designed to provide both natural and artificial illumination. A lecture theatre occupies the basement, and adjacent groups of buildings provide offices, storage and living quarters for the director. The architect of this revolutionary structure is $\mathrm{Mr}$. Frank L. Wright, of New York.

\section{Shortage of Science Teachers : New Committee of the Federation of British Industry}

THE serious effect on industry of the shortage of science teachers in schools was the subject of a conference of educationists and industrialists organized by the Federation of British Industries in January, and $a$ resolution passed at the conference recommended the Federation to set up a committee, representative of education, industry and other employers of scientists, with the aim not only of improving the supply of science teachers to the schools during the difficult years 1955-60, but also of seeking a permanent solution to the problem. Following this recommendation, the Federation has formed a Committee on the Shortage of Science Teachers, of which Dr. Percy Dunsheath (chairman of the Federation's Education Committee) will be chairman, supported by nineteen other members, each of whom will be serving in a personal capacity, and with two observers from the Ministry of Educa. tion. The nineteen members are drawn from various bodies as follows: five from schools, three from universities, one from a technical college, seven from private industry and three from government and nationalized industry.

\section{Measurement of Humidity}

THE fourth in the series of "Notes on Applied Science" prepared by the National Physical Laboratory, Teddington, deals with the "Measurement of Humidity" (pp. 20. London: H.M.S.O., 1953; 1 s. net). The measurement of humidity in the open air for meteorological purposes, which is well described in booklets issued by the Meteorological Office, is not discussed, nor are humidity measurements at very low temperatures or at high altitudes in the atmosphere for which special methods and suitable hygrometers have yet to be devised. However, humidity has to be controlled in many enclosed spaces, such as art galleries, tobacco warehouses, egg stores, textile factories and conditioning rooms. For this, high accuracy in the determination of the relative humidity is not required, and there are many types of hygrometers available to choose from. The booklet explains the physical principles underlying the various types, including wet- and dry-bulb hygrometers, dew-point instruments, and mechanical, gravimetric and electrical hygrometers, and gives detailed descriptions of some of the instruments and their particular applications. It also contains some remarks on the choice of hygrometer and instructions on the calibration of the instruments, some types of which require frequent calibration. Finally, in appendixes, definitions and references to tables of data and more detailed information are given.

\section{Council for the Promotion of Field Studies}

DEsPITE its preoccupation with finance, the Council for the Promotion of Field Studies is able to write in its report for 1952-53 that "its teaching work has continued and extended, and it is acknowledged on all sides to be of high value and significance. We can fairly claim now to have done our part to foster a method and tradition in field studies and to have made some contribution to overcoming the 